\title{
Methodology for the quantification of concrete sustainability
}

\author{
Břetislav Teplý, Tomáš Vymazal*, and Pavla Rovnaníková \\ Brno University of Technology, Faculty of Civil Engineering, 60200 Brno, Czech Republic
}

\begin{abstract}
Efficient sustainability management requires the use of tools which allow material, technological and construction variants to be quantified, measured or compared. These tools can be used as a powerful marketing aid and as support for the transition to "circular economy". Life Cycle Assessment (LCA) procedures are also used, aside from other approaches. LCA is a method that evaluates the life cycle of a structure from the point of view of its impact on the environment. Consideration is given also to energy and raw material costs, as well as to environmental impact throughout the life cycle - e.g. due to emissions. The paper focuses on the quantification of sustainability connected with the use of various types of concrete with regard to their resistance to degradation. Sustainability coefficients are determined using information regarding service life and "eco-costs". The aim is to propose a suitable methodology which can simplify decision-making in the design and choice of concrete mixes from a wider perspective, i.e. not only with regard to load-bearing capacity or durability.
\end{abstract}

\section{Introduction}

Informed sustainability management demands the employment of effective tools enabling the quantification, measurement or comparison of material, technological and construction variants. In recent years, these tools have seen development around the world and they include various indicators, indexes, certificates, comparison indicators, audits, evaluations and other systems, sometimes using various databases. In an ideal situation, economic, ecological as well as socio-cultural aspects must be included. Such tools can also be used as an effective marketing aid and as support for the transition to what is known as a circular economy. Undoubtedly, political matters have a part to play as well.

In the Czech Republic, SBTool [1] is a well-known tool for the evaluation of residential and administrative buildings. It enables the multi-criteria evaluation of a building using a particular point scale, including energy consumption and emissions assessment. Among others, SBTool makes use of Life Cycle Assessment procedures (LCA [2], [3]) and issues a "quality certificate", which provides a certain degree of quantification. LCA is a method for the evaluation of the life cycle of a structure, product or service with regard to its effect on the environment. Processes starting with the mining of mineral resources and including

\footnotetext{
*Corresponding author: tomas.vymazal@vutbr.cz
} 
their transport, production and use, through to their final processing as waste (recycling), are all taken into account. In addition, consideration is given to energy and raw material costs and to environmental impact throughout the whole life cycle. Of particular importance are air, water and soil pollution, as well as the consumption of energy and materials; in other words the ecological footprint is also evaluated. Economic evaluations naturally concern the life cycle and are therefore either Life Cycle Costing (LCC) evaluations or, if more complex, evaluations of all costs and benefits, i.e. Whole-Life Costing - WLC - see also ISO 15686-5 [4]. LCC and WLC usually do not include costs related to the effect the structure has on the environment.

The above-mentioned multi-criteria evaluation of buildings or large structures and the quantification of their sustainability are, as a rule, burdened by many uncertainties which can invalidate the results and their usability. It might thus prove useful to focus attention on partial tasks first, i.e. the evaluation and comparison of the sustainability of materials, technologies and structural elements.

This paper focuses on the quantification of the sustainability of concretes with regard to their resistance to degradation. Its aim is to present a suitable methodology which can simplify decision-making concerning the design and choice of concrete mixtures from a wider perspective, i.e. not only limited to load-bearing capacity and serviceability.

Other contexts concerning the evaluation of the life cycle and sustainability of concrete structures are dealt with in [3], [5].

\section{Quantification using a sustainability coefficient}

\subsection{Definition of coefficients}

Generally, the potential of sustainability can be calculated [6] as

$$
\Omega=\frac{\text { service-life } \times \text { performance }}{\text { impact on the environment }}=\frac{L \cdot R}{E}
$$

In this equation, "performance" $R$ means (for instance) load-bearing capacity, deformability, resistance to degradation or other properties of the material or structure in corresponding units. The service life $L$ is usually given in years and its definition is described in Section 2.2. Quantity $E$ (the "impact on the environment") is usually described as a string (sum) of data including, e.g. bound emissions of various kinds, energy consumption, wear and tear, etc. It is clear that these can be quantities of various different units which thus need to be converted into common units so as to enable the combination of all impacts into one value, $E$. These are usually financial units, and discussions concern eco-costs which, according to (for example) [2], represent the costs of measures taken to reduce the environmental impact to a sustainable level. More details can be found in Section 2.3.

It is clear that quantity $R$ can be expressed in various units and thus the resultant unit for $\Omega$ also differs from case to case. This is not practical and can complicate the decision process. Therefore authors of the present article suggest a simple normalisation of (1) using proper reference values. Sustainability can then be quantified using sustainability coefficients $k_{T U}$; all quantities $L, R$ and $E$ are divided by reference values $L_{r e f}, R_{r e f}$ and $E_{r e f}$, the $k_{T U}$ is then a dimensionless quantity, having usually a value near 1.0. 


$$
k_{T U}=\frac{\frac{L}{L_{r e f}} \cdot \frac{R}{R_{r e f}}}{\frac{E}{E_{r e f}}}
$$

An advantage of this approach is the choice to use either test results or the results of mathematical models when finding $L$ or $R$ values.

Sustainability can be quantified using $k_{T U}$ also in constituent cases, i.e. when deciding on the use of a certain material, or a particular technical or construction procedure. With this approach the following items are necessary:

i. knowledge about the service life of the material or structure in question under the given environmental and operating conditions;

ii. a decision on which parts of the lifecycle should be considered for the determination of performance in the given case;

iii. a decision on the form and severity of the environmental impact, and its expression in financial units.

If we focus on the quantification of the sustainability of structural concrete using equation (1) or (2), it is possible to avoid considering certain aspects of "performance" within the framework of the life cycle, e.g. the stage in which the structure is demolished at the end of its service life, along with socio-cultural-political aspects, thereby achieving simplification.

In frequent cases when the suitability of a proposed concrete mixture is being evaluated with regard to resistance to degradation (e.g. carbonation, the impact of chlorides, frost cycles), this resistance is usually linked directly to service life - for example, if we know the resistance of concrete against carbonation, the service life (which is considered to be the period until the possible start of corrosion of the reinforcement - the "initiation period") can be determined with the help of the depth of the concrete cover protecting the reinforcement. It is then sufficient to use as $R$ either the value of this resistance alone or just the service life and so simplify equation (1) (and similar Eq. (2)) as follows

$$
\Omega=\frac{L}{E}=\frac{\text { service life }}{\text { impacton the environment' }}
$$

or

$$
\Omega=\frac{R}{E}=\frac{\text { resistance against degradation }}{\text { impacton the environment }}
$$

This procedure can be improved further using the probabilistic approach, i.e. by considering the individual quantities in equation (1) to (4) as random quantities with a known probability distribution (e.g. as occurred for tasks concerning the service life of concrete structures described in [8]), with the output being values of statistical parameters or the probability distribution of this quantity. This enables the acquisition of further information and the possibility of comparison, e.g. the evaluation of the probability $P_{T U}$ with which a certain limit (acceptable) value $k_{T U, \text { lim }}$ could be reached using the equation

$$
P_{T U}=P\left[\left(t_{T U}-t_{T U, l i m}\right) \leq 0\right]
$$

Let us also point out that risk (the product of $P_{T U}$ and the value of the consequences of reaching such a situation) can also be quantified using the probability value. Likewise, sensitivity studies can be carried out when the probabilistic approach is used (see e.g. [8]).

Fib Bulletin 67 [5], which also presents environmental indicators based on the "performance" of a material or a structural member, focuses on the procedures and possibilities concerned with limiting the impact of concrete structures on the environment. However, these are only indicators related to the strength (load-bearing capacity) or 
thermal-insulation properties of the material; the aspect of durability (service life) is omitted entirely. Apart from this, the guide [5] only focuses on the role of $\mathrm{CO}_{2}$ emissions.

Let us point out that the need to design structures with regard to sustainability is also covered in the basic standard dealing with the reliability of structures [9], where the requirement is expressed in article 4.2.1 and the aspect of service life is also emphasized. In addition, the international document fib Mode Code 2010 [10] focuses on the performancebased design of concrete structures, listing three basic performance categories: usability (i.e. also service life), safety and sustainability. Unfortunately, the link between these quantities is not discussed in [10].

It is generally true that the design of structures with a long service life, adaptability and purposefully chosen materials alongside correct maintenance, renovation and replacement of components leads to a reduction in bound energy and eco-costs.

\subsection{Service life}

Information concerning service life is important in the context described above. There are many definitions of this quantity, articulated e.g. from the technical, operational, contractual or economic point of view. However, when evaluating reinforced concrete structures, it is advisable to work with the definition stated in the fib document [10] when evaluating sustainability, in which the service life is described using:

- relevant limit states;

- number of years;

- level of reliability (i.e. the probability of the achievement of a limit state which must not be exceeded during this period).

This concerns the technical service life, i.e. the design or remaining service life (depending on whether a new or existing structure is being evaluated). The type of limit state and the limit probability value is critical. In order to determine them, it is often necessary to model the degradation of materials over time (e.g. using the tool described in [8]), or use estimations of the service life of a structure or building obtained via e.g. the Factor method ([4] - Part 8). It is often necessary to consider the fact that the degradation of a concrete structure is a result of the combined effect of environmental and mechanical factors. In order to make service life design realistic the action of both these factors must be considered simultaneously [11].

\subsection{Eco-costs when concrete is used}

As mentioned above, "eco-costs" are expenditures on measures to be taken so as to reduce emissions to a sustainable level (as stated in e.g. [2], and in more detail in [12]). However, there are a whole range of other procedures and definitions. Political and local issues are often involved in a certain way as well.

In this context, environmental categories generally include potential global warming, ozone, emissions of acid gases, eutrophication, waste storage, etc. The corresponding ecological criteria when evaluating the impacts of concrete-based construction on the environment are mainly: bound emissions $\mathrm{CO}_{2}, \mathrm{SO}_{2}, \mathrm{NO}_{x}$, bound energy, the consumption of non-renewable resources, the consumption and pollution of water, waste, but also potential recyclability.

Of course, only some of these components can be used for each of the many conceivable cases (most frequently, the influence of $\mathrm{CO}_{2}$ is monitored). In fact, eco-costs are fictitious items and there is a certain degree of conflict between them and the pure economic aspect of a structure. Various databases exist for them, for example [13]. 
Alternatively, the price of emission allowances, which likewise involve mainly $\mathrm{CO}_{2}$ emissions, can be used when evaluating eco-costs.

Money is thought to have a time value, i.e. the future costs are discounted to a present value in order to make them comparable to current costs [14]; this can to be also considered in certain cases when dealing with eco-costs.

\section{Example of the evaluation of various kinds of concrete}

A procedure for the comparison of sustainability coefficient values, $k_{T U}$, for groups of various concretes can be described briefly in this way: all concretes in a given group must always be in the same location, suffer the same type of degradation or loading. When evaluating sustainability, a certain type of performance is considered. Service life may also be determined with regard to this type of performance. After the eco-costs have been determined, equations (2) to (4) can be used to arrive at sustainability coefficient values. This methodology can also be utilized more generally, not only for the assessment of concrete mixtures.

The composition of the mixture used in the three different concretes for the illustrative example below can be seen in Tab. 1 (A - reference mixture, Portland cement only; B with fly ash used as a substitute for a portion of the Portland cement; $\mathrm{C}$ - with fine-ground slag). The strength of concrete is considered to indicate performance; the service life is calculated using a numerical model (in the sense of the initiation stage of corrosion with regard to the carbonation of concrete). Also, the environmental impact values are shown in Tab. 2 and 3. Decisive values to be used for Eq. (2) and resulting sustainability coefficient values are listed in Tab. 4. Note, the relevant values of concrete A, i.e. $L_{r e f}=L_{A}, R_{r e f}=R_{A}$ and $E_{\text {ref }}=E_{A}$, were used as reference values.

Table 1. Composition of mixtures.

\begin{tabular}{|c|c|c|c|}
\hline Components $\left[\mathbf{k g} / \mathbf{m}^{\mathbf{3}}\right]$ & Concrete A & Concrete B & Concrete C \\
\hline CEM I 42,5 R & 389 & 290 & 290 \\
\hline Aggregate $0-4 \mathrm{~mm}$ & 812 & 812 & 812 \\
\hline Aggregate $8-15 \mathrm{~mm}$ & 910 & 910 & 910 \\
\hline Fin-ground blast furnace slag $\left(3800 \mathrm{~m}^{2} / \mathrm{kg}\right)$ & - & - & 194 \\
\hline Fly ash Dětmarovice & - & 194 & - \\
\hline Water & 161 & 182 & 160 \\
\hline
\end{tabular}

Table 2. Carbon imprint.

\begin{tabular}{|c|c|c|c|c|}
\hline Components & Concrete A & Concrete B & Concrete C & Ref. \\
\hline $\mathrm{CEM} \mathrm{I} 42.5 \mathrm{R}\left(718 \mathrm{~kg} \mathrm{CO}_{2} / \mathrm{t}\right)$ & 279 & 208 & 208 & {$[15]$} \\
\hline Slag $\left(445 \mathrm{~kg} \mathrm{CO}_{2}, / \mathrm{t}\right)$ & - & - & 107 & {$[13]$} \\
\hline Fly ash $\left(388 \mathrm{~kg} \mathrm{CO}_{2} / \mathrm{t}\right)$ & - & 75 & - & {$[13]$} \\
\hline Aggregate $\left(17 \mathrm{~kg} \mathrm{CO}_{2} / \mathrm{t}\right)$ & 29 & 29 & 29 & {$[13]$} \\
\hline
\end{tabular}




\begin{tabular}{|c|c|c|c|c|}
\hline Total $\mathrm{kg} \mathrm{CO} 2 / \mathrm{m}^{3}$ of concrete & 318 & 312 & 344 & \\
\hline
\end{tabular}

Table 3. Eco-costs.

\begin{tabular}{|c|c|c|c|c|}
\hline Components & Concrete A & Concrete B & Concrete C & Ref. \\
\hline CEM I 42.5 R $(0,109 € / t)[€]$ & 42.4 & 31.6 & 31.6 & {$[15]$} \\
\hline Slag $(0.069 € / t)[€]$ & - & - & 13.4 & {$[13]$} \\
\hline Fly ash $(0.060 € / \mathrm{t})[€]$ & - & 11.6 & - & {$[13]$} \\
\hline Aggregate $(0.007 € / \mathrm{t})[€]$ & 12.1 & 12.1 & 12.1 & {$[13]$} \\
\hline Total eco-costs $€ / \mathrm{m}^{3}$ of concrete & 54.5 & 54.3 & 57.1 & \\
\hline
\end{tabular}

Table 4. Concrete properties and the final values of coefficients $k_{T U}$.

\begin{tabular}{|c|c|c|c|}
\hline Property & Concrete A & Concrete B & Concrete C \\
\hline Cube 60-day strength [MPa] & 71.9 & 47.2 & 70.5 \\
\hline Service life [years]* & 125 & 73 & 151 \\
\hline Eco-costs [€] & 54.5 & 54.3 & 57.1 \\
\hline $\boldsymbol{k}_{\boldsymbol{T} U}$ according to (2) & 1 & 0.38 & 1.13 \\
\hline
\end{tabular}

* Determined by calculating the period needed for depassivation of the reinforcement to occur via carbonation (FReET-D [8], model Carb4b, $k=0.4$ for concrete B and $k=0.6$ for C) for a $30 \mathrm{~mm}$ concrete cover. Other input values: $\mathrm{CO}_{2}$ in the ambient air is $820\left[\mathrm{mg} / \mathrm{m}^{3}\right]$, $\mathrm{RH}=70 \%$.

Es follows from resulting $k_{T U}$ values (see Tab. 4), the best choice from the view of sustainability is concrete $\mathrm{C}$ in spite of the fact that it bring highest eco-costs then variants $\mathrm{A}$ and $\mathrm{B}-$ this is evidently influenced by the longest service life.

\section{Conclusions}

The paper presents a helpful tool for the management of sustainability, which enables its quantification and the comparison of mixture variants for the production of concrete with an emphasis on degradation effects (e.g. strength, resistance to carbonation, resistance against the penetration of chloride ions, frost resistance, and others) and hence issues of durability. Simple formulae in which service life, performance and eco-costs appear are presented for sustainability coefficients, $k_{T U}$. The aim of the task is to compare the variants of the group of the mixtures being examined, and not to determine/describe the sustainability value directly. An illustrative example can be found in Section 3.

\section{Acknowledgement}

This work has been supported by project No. 17-14302S "Experimental analysis of the early-age volume changes in cement-based composites", supported by the Czech Science Foundation and project No. No. LO1408 "AdMaS UP - Advanced Materials, Structures 
and Technologies", supported by Ministry of Education, Youth and Sports under the "National Sustainability Programme I".

\section{References}

1. National certification tool for expressing the level of quality of buildings. http://www.sbtool.cz/

2. fib Bulletin 28 Environmental design. (International Federation for Structural Concrete (fib), Lausanne, Switzerland, 2004).

3. fib Bulletin 71 Integrated life cycle assessment of concrete structures (International Federation for Structural Concrete (fib), Lausanne, Switzerland, 2013).

4. ISO 15686 Buildings and constructed assets -- Service life planning - Parts 1 to 8.

5. fib bulletin No. 67 Guidelines for green concrete structures (International Federation for Structural Concrete (fib), Lausanne, Switzerland, 2012).

6. H. S. Müller, M. Haist, M. Vogel, Construction and Building Materials, 67, 321-337, (2014).

7. Ch. F. Hendriks, J. G. Vogtländer, G. M. T. Jansen, WIT Transactions on State of the Art in Science and Engineering, 51 (2011).

8. D. Novák, M. Vořechovský, B. Teplý, Advances in Engineering Software. 72, 179192, (2014).

9. ISO 2394 - General principles on reliability for structures (2015).

10. fib bulletin No. 65 and 66 (International Federation for Structural Concrete (fib), Lausanne, Switzerland, 2012).

11. D. Vořechovská, M. Šomodíková, J. Podroužek, D. Lehký, B. Teplý, Computers and Concrete, 20/1, 99-110 (2017).

12. J.G. Vogtländer, H.C. Brezet, Ch.F. Hendriks, Int. J. LCA, 3(6), 157-166 (2001).

13. www.design-4-sustainability.com/ecocosts

14. Y. Zhang, Sustainability, 9(6), 922 (2017).

15. https://www.svcement.cz/data/data-2016

16. https://www.eru.cz/-/prumerna-cena-emisni-povolenky-pro-rok-2016 